EMPIRICAL STUDIES OF THE ARTS, Vol. 28(1) 3-17, 2010

\title{
THE AMERICAN IDOL EFFECT: ARE STUDENTS GOOD JUDGES OF THEIR CREATIVITY ACROSS DOMAINS?
}

\author{
JAMES C. KAUFMAN \\ MICHELLE L. EVANS \\ California State University, San Bernardino \\ JOHN BAER \\ Rider University
}

\begin{abstract}
Students are often asked to judge their own creativity. There is some evidence that such judgments correlate modestly with other self-report data and some divergent thinking test measures. Only limited work, however, has been done comparing self-reported creativity with actual creative performance. Because levels of self-reported creativity might vary across domainswhich would allow greater likelihood of accuracy of such reports-we examined self-reports of creativity in four domains and compared these with expert ratings of subjects' work in those domains (as judged using the Consensual Assessment Technique). Subjects were 78 fourth-grade students. The students did not predict uniform levels of creativity for themselves across domains (all self-assessments correlated across domains less than .30). However, these predictions did not match expert ratings of the students' creative products in each domain. These results challenge the validity of self-assessments of creativity among students of this age, even when the students are given the opportunity to give themselves different creativity ratings in different domains.
\end{abstract}

(c) 2010, Baywood Publishing Co., Inc. doi: 10.2190/EM.28.1.b

http://baywood.com 


\section{4 / KAUFMAN, EVANS AND BAER}

Are people good judges of their own creativity? Certainly, those who regularly watch American Idol or similar shows have seen much anecdotal evidence that the answer may be "no." Many contestants have demonstrated a sincere passion for singing and a belief in their own abilities - yet with strikingly little talent to go with it. Perhaps the most salient example is William Hung, a Berkeley engineering student, who performed an enthusiastic yet poorly received song on the popular show, prompting one judge to remark, "You can't sing, you can't dance, so what do you want me to say?" (Bulwa, 2004). His singing actually became popular because Hung's passion and belief in his own abilities were such a mismatch with his actual talent; people often attended his performances for humor rather than musical purposes.

However, it is not only American Idol that gives people a chance to demonstrate the disconnect between their opinions about their beliefs and their actual talent. The vanity press publishers who advertise regularly in the New York Review of Books offer titles and descriptions of books that have been self-published that may not immediately strike a reader as being quality creative work. One such press, Vantage Press, sells its services by asking questions that appeal to people's lack of knowledge about their own creative capabilities, such as, "Is your subject so timely that you can't afford to wait two years-or two months for publisher's reaction to your manuscript?" They also tell their potential customers that:

If you're considering subsidy publishing, you're in elite company. Literary luminaries who gained renown after publishing their own work at their own expense comprise a veritable "Who's Who"-novelists, poets, playwrights, scholars. . . For example, Thomas Gray, Elizabeth Barrett Browning, Alexander Pope, Percy Bysshe Shelley, Alfred Lord Tennyson. . . . (Vantage Press, 2008)

Who are these people who audition for American Idol despite a lack of ability and send unpublishable manuscripts to vanity presses? Such people would seem to be low in metacognitive skill, the ability to monitor one's own learning, perform self-evaluation, and then make plans accordingly (Everson \& Tobias, 1998; Flavell, 1979). Someone who was high in metacognitive abilities would know his or her limitations, be able to seek help, and estimate success with reasonably high accuracy. There are some theoretical links between metacognition and creativity (e.g., Naglieri \& Kaufman, 2001). Several theorists, such as Boyce, Van Tassel-Baska, Burruss, Sher, and Johnson (1997), Feldhusen and Goh (1995), Jausovec (1994), and Davidson and Sternberg (1998) have argued that metacognition is connected to creative problem solving and that someone who is high in metacognitive ability should be a more creative problem solver.

So it has been argued that high metacognitive ability should be associated with better and more creative performance, and the flipside of this connection-that those lacking metacognitive skill will generally exhibit little creativity-has also 
been proposed by Kruger and Dunning (1999; see also Dunning, 2005; Dunning, Johnson, Ehrlinger, \& Kruger, 2003; Kruger, 1999). People who do poorly in intellectual (and social) realms may suffer from a "double whammy" - they are not only underperformers, but they also have lower metacognitive abilities and therefore are unable to recognize their poor performance. Indeed, this line of research has led at least one blogger to coin the term the "American Idol Effect" (Koehler, 2006a, 2006b).

This question has only recently been addressed in the creativity literature. Much of the work on self-assessment has been led by Adrian Furnham and his colleagues. Most of his studies have looked at self-assessed intelligence, finding medium-level correlations ( .30 to .50$)$ between self-ratings and test scores (e.g., Chamorro-Premuzic, Furnham, \& Moutafi, 2004; Furnham \& ChamorroPremuzic, 2004; Paulhus, Lysy, \& Yik, 1998). He has conducted some studies on self-assessed creativity (Furnham, 1999; Furnham, Zhang, \& ChamorroPremuzic, 2006), finding that self-assessed creativity was significantly related to creativity as measured by the Barron Welsh Art Scale. In other studies, Park, Lee, and Hahn (2002) found self-reported creativity to significantly correlate with all scores on the Torrance Tests of Creative Thinking (TTCT) except for fluency, and Phillips (1973) found that self-assessments differed between high-scorers on the TTCT and low-scorers.

Investigations that focus on non-psychometric measures are less clear. Selfreport measures tend to correlate highly with each other (e.g., Fleenor \& Taylor, 1994; Goldsmith \& Matherly, 1988; Kaufman \& Baer, 2004), although selfreport measures do not appear to correlate highly with self-reported creative activities (Eisenman \& Grove, 1972). Lee, Day, Meara, and Maxwell (2002) used three measures of creativity (verbal, pictorial, and self-report) and found little relationship among the three measures. Priest (2006) found that students' self-assessment of the creativity of their musical compositions was not predictive of expert ratings of these same compositions.

How do self-assessments stack up against creative performance in multiple domains? Are people better judges of their own creative abilities in some areas, but not others? The goal of this investigation was to begin such a line of research by both examining the relationship between metacognition and creativity and exploring the question of the validity of self-assessments. Indeed, if people are not good judges of their own creative ability, then the utility of such self-assessments may be quite low (Kaufman, Plucker, \& Baer, 2008).

This present study investigated creativity in fourth graders, in part because this age is rife with meaning in creativity literature. Some scholars, most notably Torrance, have argued that there is a "fourth grade slump," in which creative performance suffers in this year due to socialization and other factors (Torrance, $1962,1965,1968)$. Other research directly opposes this idea, arguing for a surge of creativity in the fourth grade (Baer, 1996; Charles \& Runco, 2001; Claxton, Pannells, \& Rhoads, 2005; Smith \& Carlsson, 1983, 1985). Regardless of whether 
fourth grade represents a waxing or waning of creativity abilities, it seems to be an age that is significant in discussions of creativity development.

\section{METHOD}

\section{Participants}

A total of 78 fourth-grade students from three public school classrooms from northern California participated. The average age was 9.5 years old with a range of 9-11 years old. Thirty-five percent of the participants were male and $65 \%$ were female. Of the races that were represented, $35 \%$ were white European American, 35\% were Hispanic, 19\% were multi-racial or of a not listed race, 9\% were Asian American, and 2\% were American Indians. The average household had an income of $\$ 70,000-\$ 90,000$ dollars with a range of less than $\$ 15,999$ to over $\$ 90,000$. The only incentive the students received for participation was a mechanical pencil.

\section{Materials and Procedure}

First, an informed consent form, which included information on the age, ethnicity, and gender of the child, was sent to the students' parents. The children with permission from their parents were themselves asked for their permission to participate in the study. Only children who gave their consent and had parental consent participated in the study. Children without full consent were moved to another classroom and participated in another classroom's regularly scheduled activities.

Participants were asked to answer an eight-item questionnaire that asked them about their creativity in math, science, writing, and art, with two items devoted to each domain. One question asked, "How creative in XXX do you think you are?" The second question asked, "I think I have a good imagination when I am XXX." Participants responded with either "not very," "somewhat," or "very." These questions were based on past domain-related creativity surveys (e.g., Kaufman, 2006; Kaufman \& Baer, 2004) and were written to be understandable by younger children.

Over the next few days participants completed four creative tasks (each requiring approximately 60 minutes) to measure the four domains of creativity: math, science, writing, and art. Only one creative task was presented at a time per class per day, so the children could all focus solely on the single task. The order was alternated across the classrooms to minimize order effects.

For every task the materials each student received were identical. For the art domain task, each participant received a blank $8.5^{\prime \prime} \times 11^{\prime \prime}$ piece of white paper, glue, crayons, and colored construction paper designs. Each participant was 


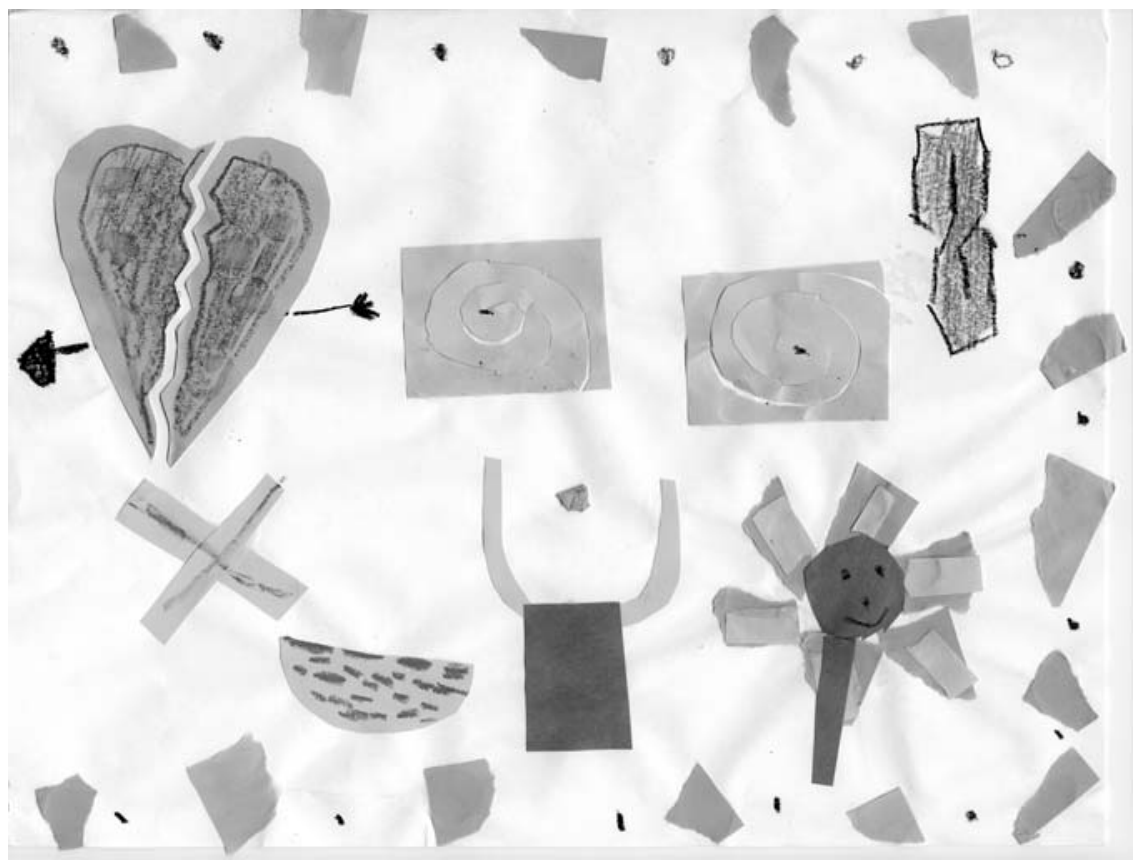

Figure 1. Highest scoring example of visual arts creativity, with 20.5 out of 25 points from the five raters.

Note: Although it is hard to tell from this scan, the collage has the ability to be 3D. The swirls can expand and the heart opens.

asked to use these materials to make an "interesting, silly design" (Baer, 1993). An example of the highest-rated collage can be seen in Figure 1, and the lowestrated collage can be seen in Figure 2.

For the math domain, task participants were given a pencil and a piece of lined paper on which they wrote a creative equation. They were given samples of equations, such as $2+2=2+2$ and $(9+4)-6=4+\mathrm{A}$. Then they were asked to write an interesting, original equation (Baer, 1993). This task was reasonable for fourth grade students. Fourth grade curriculum states that all students should be able to do low level algebra (National Center for Education Statistics, 2006). An example of a highly-scored response is $(5 \times 4)+78=78+\mathrm{D}$. Low-rated responses were generally a list of random numbers.

For the writing domain, participants were asked to write a poem on the topic of the four seasons. Participants were supplied with lined paper and a pencil. The form, style, and length of the poem were not specified. Participants were told 


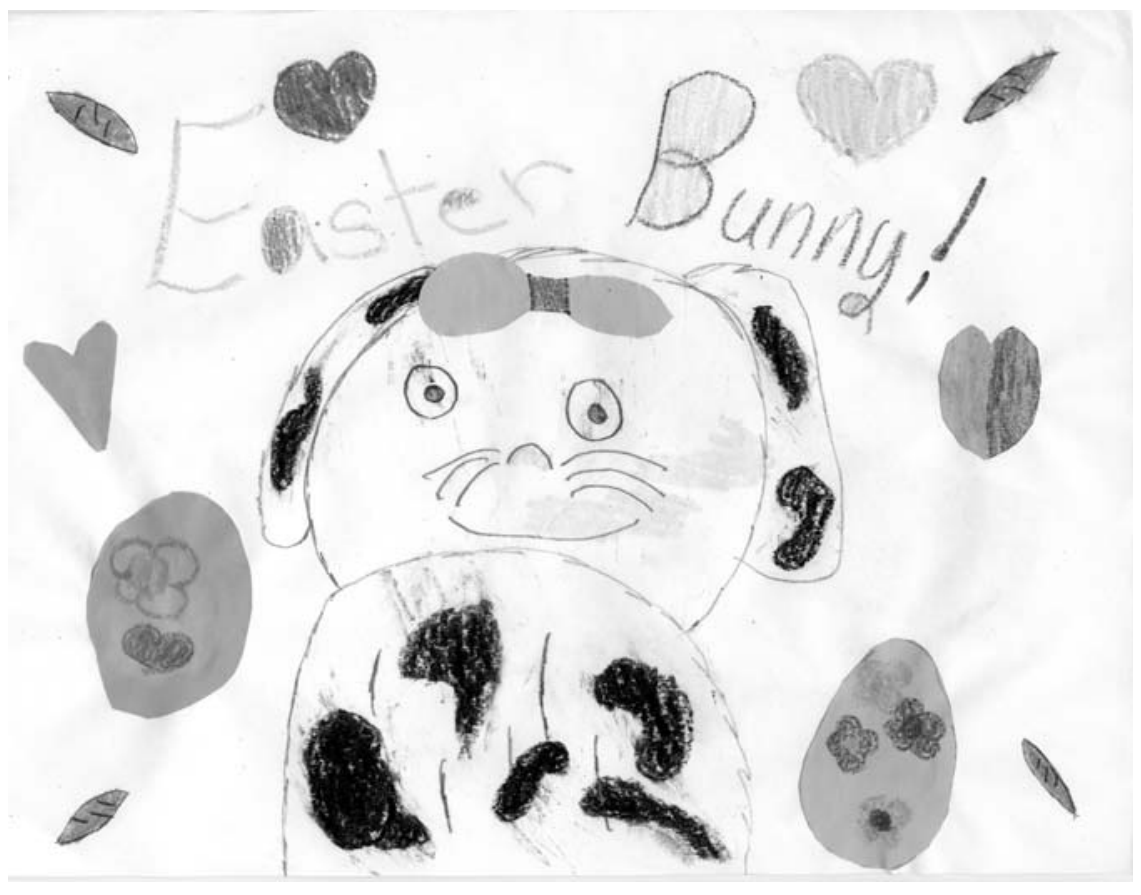

Figure 2. Lowest scoring example of visual arts creativity, with 5.5 out of 25 points from five raters.

that except for the topic, everything else about the poem was up to them (Baer, 1993). Examples of high and low rated poems are presented in Appendix 1.

For the science domain, students were provided with a pencil and a handout that had prompts and spaces for them to write on. Students were asked to make up a new animal and describe how it adapted to the habitat it lives in. The complete instructions and questions are presented in Appendix 2. This task was appropriate for a fourth grade student because basic life science concepts are integrated into every level of education. An example of a highly-rated response to the last question in the set ("Now that the Zooks have lived in a tropical place for twenty years, what do you think that the new Zook babies will look like?") was "They will have a little tail, no teeth, a light orange color. The height will be 39 inches." A low-rated response was "My dogs don't have babies yet."

The studies were conducted in the participants' classrooms. The teacher was present, but the researcher carried out all aspects of the study. Once the survey packet or creative product was finished, it was collected by the researcher. A 
sticker with the child's identification number on it was placed over the child's name on the back of each creative product. This identification number was linked to the child's demographic information.

\section{Raters}

Five elementary classroom teachers were selected as being appropriate experts to rate the creative products, consistent with past findings that show classroom teachers as agreeing with content experts when rating children's creative work (Baer, Kaufman, \& Gentile, 2004; Kaufman, Gentile, \& Baer, 2005). No rater was a classroom teacher for any of the children in the study, and all products were presented with no identifying information. Raters were asked to evaluate products on a 1.0-5.0 scale, with 1.0 being least creative and 5.0 being most creative. Raters were asked to assign creativity ratings based on their own personal definitions of creativity; no additional guidance, descriptors, or material on creativity were provided. Raters did not meet or talk about their ratings with one another or with the experimenters. This format is consistent with the Consensual Assessment Technique as developed by Amabile $(1982,1996)$ and refined by others (Baer, 1993, 1998; Baer et al., 2004; Kaufman, Baer, Cole, \& Sexton, 2008; Kaufman, Lee, Baer, \& Lee, 2007).

\section{RESULTS}

The two items for each of the four domain-based self-assessments showed inter-item correlations as follows: For the math items, $r=.57$; for the art items, $r=.45$; for the writing items, $r=.52$; and for the science items, $r=.58$. Using the Spearman-Brown prediction formula yields scores of $r=.73$ (math), $r=.62$ (art), $r=.68$ (writing), and $r=.73$ (science), all of which are at the moderate/acceptable level (Kaplan \& Saccuzzo, 2005). The two items were therefore summed to form a single score for each domain.

Next, an inter-rater reliabilities analysis was run using Cronbach's alpha to determine if there was sufficient agreement among the raters. Coefficient alphas were .89 for the science task, .81 for the writing task, .80 for the art task, and .78 for the math task. All of the domains met the cut-off criteria for sufficient inter-rater reliability of .70 (Streiner, 2003). Expert ratings were therefore summed across each domain to create a single score for each domain.

Means and standard deviations for all four domain-based self-assessments and for all four domain-based product ratings are presented in Table 1.

Correlations were computed to see how expert-rated creativity compared across domains. These results can be seen in Table 2. Correlations were also computed to see how self-assessed creativity compared across domains. These results can be seen in Table 3. Finally, correlations were computed to see how self-assessed and expert-rated creativity compared for each domain. Self-assessed creativity and 
10 / KAUFMAN, EVANS AND BAER

Table 1. Means and Standard Deviations for Rated and Self-Assessed Creativity by Domain

\begin{tabular}{lcc}
\hline & Mean & $\begin{array}{c}\text { Standard } \\
\text { deviation }\end{array}$ \\
\hline Self-assessed math & 4.5 & 1.2 \\
Self-assessed art & 5.4 & 0.9 \\
Self-assessed science & 4.6 & 1.2 \\
Self-assessed writing & 4.6 & 1.1 \\
Expert-rated math & 10.7 & 4.2 \\
Expert-rated art & 12.7 & 3.7 \\
Expert rated science & 13.2 & 4.8 \\
Expert-rated writing & 12.8 & 4.2 \\
\hline
\end{tabular}

Note: Self-assessments were calculated on a 3-point scale (Not Very, Somewhat, Very) summed over two items. Expert-ratings were given on a 1-5 scale, summed over five raters.

Table 2. Correlations for Expert-Rated Creativity across Four Domains

\begin{tabular}{lcccc}
\hline & Science & Writing & Art & Math \\
\hline Science & - & $.48^{\star *}$ & .07 & -.03 \\
Writing & - & - & $.30^{\star}$ & .14 \\
Art & - & - & - & .23 \\
\hline
\end{tabular}

${ }^{\star} p<.05 ;{ }^{* \star} p<.01$

Table 3. Correlations for Self-Rated Creativity across Four Domains

\begin{tabular}{lcccc}
\hline & Science & Writing & Art & Writing \\
\hline Science & - & .10 & $.25^{\star}$ & $.28^{\star}$ \\
Writing & - & - & .22 & .07 \\
Art & - & - & - & -.07 \\
\hline
\end{tabular}

${ }^{\star} p<.05$. 
expert-rated creative performance correlated -.07 in science, -.22 in writing, -.08 in art, and .07 in math. None of these correlations was significant.

\section{DISCUSSION}

The 78 fourth-grade participants in this study were remarkably poor predictors of their own creativity (as measured by actual creative performance) in all four domains (science, writing, art, and math). They did not predict their creativity to be uniformly high (or low) across domains - the correlations between selfassessments of creativity across domains were all less than .30. This suggests that the failure to predict their own creativity successfully was not due to a failure to think of their creativity differently in different domains.

Nor was their creative performance uniform across domains. As in past research, expert ratings of creativity across performance domains showed only very limited evidence of domain generality (Baer, 1991, 1993, 1994, 1998; Runco, 1989). Of six correlations, only two were statistically significant (creativity in writing had correlations of .48 with science creativity and .30 with art creativity). Because the science task included a significant writing component (participants needed to describe, in writing, a new animal and its relation to its habitat), that correlation is not surprising. The lack of homogeneity in either the self-assessments of the participants or the ratings of their creative performances across domains does not suggest that over-generalization of their ratings across domains could have caused the poor predictions the participants made of their own creativity. It should be noted that the inter-reliabilities of the expert ratings of creativity within each domain were quite good, ranging from .78 to .89 . This would therefore seem to rule out lack of consistency in these ratings as a possible explanation for the students' inability to assess with any accuracy their own levels of creativity in each domain.

These fourth-grade students' lack of insight into their own creativity should not be surprising, given both the line of research by Kruger and Dunning (1999) and Furnham and Chamorro-Premuzic (2004). Indeed, DeNisi and Shaw (1977), in a study of workplace performance, argued 30 years ago that although self-reported ability did have some use, it did not predict test scores and should not be used in place of ability tests. College students cannot accurately estimate their own IQs (e.g., Paulhus et al., 1998), despite the far more extensive information they would be expected to have received in this area in comparison to knowledge about their own creativity that the fourth-grade participants of this study might be likely to have. Given such past findings, the fact that the self-estimates of creativity that we observed showed so little connection to measures of actual creative performance should perhaps not be considered an unexpected finding.

It is important to note, however, that these findings seem to contradict recent work on creative self-efficacy, which refers to self-judgments and personal identification with being creative. Much of the research on creative self-efficacy is 
rooted in the concept of self-efficacy (one's beliefs about one's own abilities; see Bandura, 1997). Tierney and Farmer (2002) proposed the concept of creative self-efficacy as representing a person's beliefs about how creative he or she can be. These beliefs are often rooted in a situational or narrow context (e.g., Jaussi, Randel, \& Dionne, 2007). Beghetto (2006) has shown that high creative selfefficacy is related to teacher feedback on creative performance. It is possible that the brief items measuring self-assessed creative ability were not seen as meaningful enough to tap into a child's creative self-efficacy. If the child truly reflected on his or her abilities, then these responses may have resulted in more accurate perceptions of one's creative performance.

Similarly, although the artistic and writing creativity tasks have been commonly used with children (Amabile, 1982, 1996; Baer, 1993; Baer et al., 2004), the math equation task has been used less often (Baer, 1993), and the science task was new to this study. It is certainly possible that the raters may have been focused on simple competence more than creativity - the low-rated example of the child who stated that his dog had not yet had puppies had almost nothing to do with the task at hand, and many low-rated math equations were simply incoherent. In addition, although past studies have shown that school teachers are appropriate experts (Baer et al., 2004; Kaufman et al., 2008), their ratings may have been less valid than had professional scientists, artists, writers, and mathematicians rated each response.

Regardless, this study does indicate that self-assessed creativity shows poor connection to actual creative abilities across domains. These findings suggest that any measures of self-reported creativity used in research or in student placement in gifted/talented programs should be evaluated skeptically and given little if any weight, at least for students of this age. Self-reported creativity may be an interesting variable in its own right (just as American Idol contestants' ofteninflated judgments of their own abilities are apparently of considerable interest to television viewers, even - perhaps especially-when those self-assessments bear so little relationship to contestants' actual ability), but such self-reports may nonetheless tell us very little if anything about actual creative abilities.

\section{APPENDIX 1}

Highest scoring example of written creativity, with 21 out of 25 points from the five raters.

fall

Me \& my friend went out

side in the fall \& made a

pile of leafs and jumped in them 


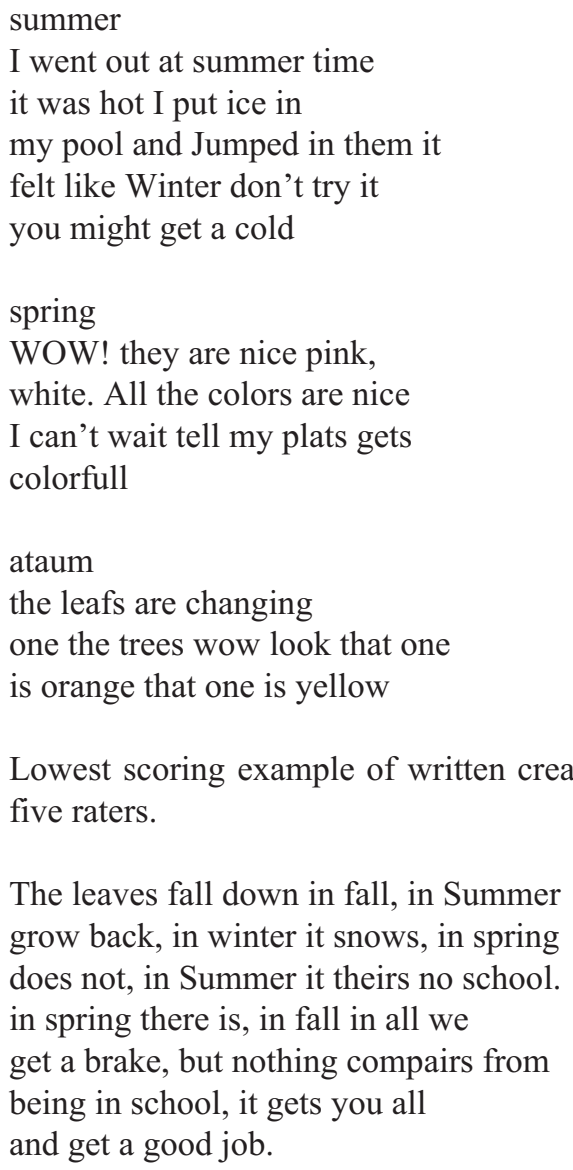
five raters.

The leaves fall down in fall, in Summer grow back, in winter it snows, in spring does not, in Summer it theirs no school. in spring there is, in fall in all we get a brake, but nothing compairs from being in school, it gets you all and get a good job.

Lowest scoring example of written creativity, with 7 out of 25 points from the

\section{APPENDIX 2 Scientific Creativity Task Instructions}

There is an animal named Zook that lives here on earth. A Zook is light in color, has big sharp teeth, and a tail.

1. What type of animal do you think a Zook is?

2. Why?

3. Where do you think Zooks live?

4. How would the habitat meet the needs of the Zook?

5. What living and nonliving things would be in this habitat?

6. What do you think Zooks eat?

7. How do they get their food? 


\section{4 / KAUFMAN, EVANS AND BAER}

Now pretend that all the Zooks in the world were moved to a tropical location.

1. How will the Zooks' lives change?

2. Now that the Zooks have lived in a tropical place for twenty years, what do you think that the new Zook babies will look like?

\section{ACKNOWLEDGMENTS}

The authors would like to thank the Visalia Unified School District and Hurley Elementary school for their participation, and Jeanne Evans and Laurie Evans and their classes for their assistance. Ms. Evans is now at Mount Saint Mary's College.

\section{REFERENCES}

Amabile, T. M. (1982). Social psychology of creativity: A consensual assessment technique. Journal of Personality and Social Psychology, 43, 997-1013.

Amabile, T. M. (1996). Creativity in context: Update to the social psychology of creativity. Boulder, CO: Westview.

Baer, J. (1991). Generality of creativity across performance domains. Creativity Research Journal, 4, 23-39.

Baer, J. (1993). Creativity and divergent thinking: A task-specific approach. Mahwah, NJ: Lawrence Erlbaum.

Baer, J. (1994). Divergent thinking is not a general trait: A multi-domain training experiment. Creativity Research Journal, 7, 35-46.

Baer, J. (1996). Does artistic creativity decline during elementary school years? Psychological Reports, 78, 927-930.

Baer, J. (1998). The case of domain specificity of creativity. Creativity Research Journal, 11, 173-177.

Baer, J., Kaufman, J. C., \& Gentile, C. A. (2004). Extension of the Consensual Assessment Technique to non parallel creative products. Creativity Research Journal, 16, 113-117.

Bandura, A. (1997). Self-efficacy: The exercise of control. New York: Freeman.

Beghetto, R. A. (2006). Creative self-efficacy: Correlates in middle and secondary students. Creativity Research Journal, 18, 447-457.

Boyce, L. N., VanTassel-Baska, J., Burruss. J. D., Sher, B. T., \& Johnson. D. T. (1997). A problem-based curriculum: Parallel learning opportunities for students and teachers. Journal for the Education of the Gifted, 20, 363-379.

Bulwa, D. (2004, February 11). UC's accidental pop star. San Francisco Chronicle. Retrieved April 16, 2008, from http:/www.sfgate.com/cgi-bin/article.cgi?f=/c/a/ 2004/02/11/BAGCM4U0UR1.DTL

Chamorro-Premuzic, T., Furnham, A., \& Moutafi, J. (2004). The relationship between estimated and psychometric personality and intelligence scores. Journal of Research in Personality, 38, 505-513.

Charles, R. E., \& Runco, M. A. (2001). Developmental trends in the evaluation and divergent thinking of children. Creativity Research Journal, 13, 417-437. 
Claxton, A. F., Pannells, T. C., \& Rhoads, P. A. (2005). Developmental trends in the creativity of school-age children. Creativity Research Journal, 17, 327-335.

Davidson. J. E., \& Sternberg. R. J. (1998). Smart problem solving: How metacognition helps. In D. J. Hacker. J. Dunloskv, \& A. C. Graeser (Eds.), Metacognition in educational theory and practice (pp. 47-68). Mahwah, NJ: Lawrence Erlbaum.

DeNisi, A. S., \& Shaw, J. B. (1977). Investigation of the uses of self-reports of abilities. Journal of Applied Psychology, 62, 641-644.

Dunning, D. A. (2005). Self-insight: Roadblocks and detours on the path to knowing thyself. New York: Psychology Press.

Dunning, D., Johnson, K., Ehrlinger, J., \& Kruger, J. (2003). Why people fail to recognize their own incompetence. Current Directions in Psychological Science, 12, $83-86$.

Eisenman, R., \& Grove, M. S. (1972). Self-ratings of creativity, semantic differential ratings, and preferences for polygons varying in complexity, simplicity, and symmetry. Journal of Psychology: Interdisciplinary and Applied, 81, 63-67.

Everson, H. T., \& Tobias, S. (1998). The ability to estimate knowledge and performance in college: A metacognitive analysis. Instructional Science, 26, 65-79.

Feldhusen. J. F., \& Goh. B. E. (1995). Assessing and accessing creativity: An integrative review of theory, research, and development. Creativity Research Journal, $8,231-247$.

Flavell, J. (1979). Metacognition and cognitive monitoring: A new area of cognitive developmental inquiry. American Psychologist, 34, 906-911.

Fleenor, J. W., \& Taylor, S. (1994). Construct validity of three self-report measures of creativity. Educational and Psychological Measurement, 54, 464-470.

Furnham, A. (1999). Personality and creativity. Perceptual and Motor Skills, 88, 407-408.

Furnham, A., \& Chamorro-Premuzic T. (2004). Estimating one's own personality and intelligence scores. British Journal of Psychology, 95, 145-160.

Furnham, A., Zhang, J., \& Chamorro-Premuzic, T. (2006). The relationship between psychometric and self-estimated intelligence, creativity, personality, and academic achievement. Cognition and Personality, 25, 119-145.

Goldsmith, R. E., \& Matherly, T. A. (1988). Creativity and self-esteem: A multiple operationalization validity study. Journal of Psychology, 122, 47-56.

Jausovec, N. (1994). Metacognition in creative problem solving. In M. A. Runco (Ed.), Problem finding, problem solving, and creativity (pp. 77-95). Norwood, NJ: Ablex.

Jaussi, K. S., Randel, A. E., \& Dionne, S. D. (2007). I am, I think I can, and I do: The role of personal identity, self-efficacy, and cross-application of experiences in creativity at work. Creativity Research Journal, 19, 247-258.

Kaplan, R. M., \& Saccuzzo, D. P. (2005). Psychological testing. Belmont, CA: Thomson Wadsworth.

Kaufman, J. C. (2006). Self-reported differences in creativity by gender and ethnicity. Journal of Applied Cognitive Psychology, 20, 1065-1082.

Kaufman, J. C., \& Baer, J. (2004). Sure, I'm creative- but not in math!: Self-reported creativity in diverse domains. Empirical Studies of the Arts, 22, 143-155.

Kaufman, J. C., Baer, J., Cole, J. C., \& Sexton, J. D. (2008). A comparison of expert and nonexpert raters using the Consensual Assessment Technique. Creativity Research Journal, 20, 171-178. 
Kaufman, J. C., Gentile, C. A., \& Baer, J. (2005). Do gifted student writers and creative writing experts rate creativity the same way? Gifted Child Quarterly, 49, 260-265.

Kaufman, J. C., Lee, J., Baer, J., \& Lee, S. (2007). Captions, consistency, creativity, and the consensual assessment technique: New evidence of validity. Thinking Skills and Creativity, 2, 96-106.

Kaufman, J. C., Plucker, J. A., \& Baer, J. (2008). Essentials of creativity assessment. New York: Wiley.

Koehler, R. (2006a). Beware the American Idol effect. The honest hypocrite. Retrieved January 24, 2007, from http://honesthypocrite.blogspot.com/2006/01/bewareamerica-idol-effect.html

Koehler, R. (2006b). Scientific proof of the American Idol Effect. The honest hypocrite. Retrieved January 24, 2007, from http://honesthypocrite.blogspot.com/2006/04/ scientific-proof-of-american-idol.html

Kruger, J. (1999). Lake Wobegone, be gone! The "below-average effect" and the egocentric nature of comparative ability judgments. Journal of Personality and Social Psychology, 77, 221-232.

Kruger, J., \& Dunning, D. (1999). Unskilled and unaware of it: How difficulties in recognizing one's own incompetence lead to inflated self-assessments. Journal of Personality and Social Psychology, 77, 1121-1134.

Lee, J., Day, J. D., Meara, N. M., \& Maxwell, S. E. (2002). Discrimination of social knowledge and its flexible application from creativity: A multitrait-multimethod approach. Personality and Individual Differences, 32, 913-928.

Naglieri, J. A., \& Kaufman, J. C. (2001). Understanding intelligence, giftedness, and creativity using the PASS theory. Roeper Review, 23, 151-156.

National Center for Education Statistics. (2006). Retrieved June 9, 2006, from http:// nces.ed.gov/nationsreportcard/nrc/reading math 2005/s0017.asp?printver

Park, M., Lee, J., \& Hahn, D. W. (2002). Self-reported creativity, creativity, and intelligence. Poster presented at the American Psychological Association, Chicago.

Paulhus, D., Lysy, D., \& Yik, M. (1998). Self-report measures of intelligence: Are they useful as proxy IQ tests? Journal of Personality, 66, 523-555.

Phillips, V. K. (1973). Creativity: Performance, profiles, and perceptions. Journal of Psychology: Interdisciplinary and Applied, 83, 25-30.

Priest, T. (2006). Self-evaluation, creativity, and musical achievement. Psychology of Music, 34, 47-61.

Runco, M. A. (1989). The creativity of children's art. Child Study Journal, 19, 177-190.

Smith, G. J. W., \& Carlsson, I. (1983). Creativity in early and middle school years. International Journal of Behavioral Development, 6, 167-195.

Smith, G. J. W., \& Carlsson, I. (1985). Creativity in middle and late school years. International Journal of Behavioral Development, 8, 329-343.

Streiner, D. L. (2003). Starting at the beginning: An introduction to coefficient alpha and internal consistency. Journal of Personality Assessment, 80, 99-103.

Tierney, P., \& Farmer, S. M. (2002). Creative self-efficacy: Its potential antecedents and relationship to creative performance. Academy of Management Journal, 45, 1137-1148.

Torrance, E. P. (1962). Guiding creative talent. Englewood Cliffs, NJ: Prentice-Hall.

Torrance, E. P. (1965). Rewarding creative behavior. Englewood Cliffs, NJ: Prentice-Hall. 


\section{AMERICAN IDOL EFFECT / 17}

Torrance, E. P. (1968). A longitudinal examination of the fourth grade slump in creativity. Gifted Child Quarterly, 12, 195-199.

Vantage Press (2008). Online brochure. Retrieved April 16, 2008, from http://www. vantagepress.com/broc2000.htm

Direct reprint requests to:

James C. Kaufman

Learning Research Institute

California State University at San Bernardino

Department of Psychology

5500 University Parkway

San Bernardino, CA 92407

e-mail: jkaufman@csusb.edu 